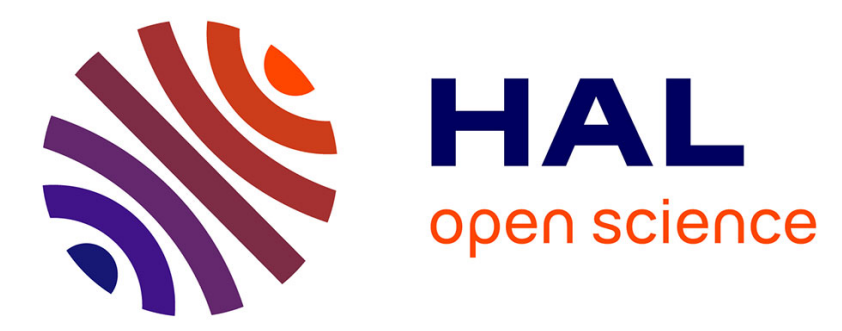

\title{
When to depart from a stopover site? Time since arrival matters more than current weather conditions
}

Sébastien Roques, Pierre-Yves Henry, Gaétan Guyot, Bruno Bargain, Emmanuelle Cam, Roger Pradel

\section{- To cite this version:}

Sébastien Roques, Pierre-Yves Henry, Gaétan Guyot, Bruno Bargain, Emmanuelle Cam, et al.. When to depart from a stopover site? Time since arrival matters more than current weather conditions. Ornithology, 2021, 10.1093/ornithology/ukab057 . hal-03452461

\section{HAL Id: hal-03452461 https://hal.science/hal-03452461}

Submitted on 26 Nov 2021

HAL is a multi-disciplinary open access archive for the deposit and dissemination of scientific research documents, whether they are published or not. The documents may come from teaching and research institutions in France or abroad, or from public or private research centers.
L'archive ouverte pluridisciplinaire HAL, est destinée au dépôt et à la diffusion de documents scientifiques de niveau recherche, publiés ou non, émanant des établissements d'enseignement et de recherche français ou étrangers, des laboratoires publics ou privés. 


\title{
When to depart from a stopover site? Time since arrival matters more than current weather conditions
}

\author{
Sébastien Roques, ${ }^{1,2}$ Pierre-Yves Henry, ${ }^{3,4}$ Gaétan Guyot, ${ }^{5}$ Bruno Bargain, ${ }^{5}$ Emmanuelle Cam, ${ }^{2,6}$ and \\ Roger Pradel ${ }^{1}$
}

\author{
$1 \quad$ CEFE, Univ Montpellier, CNRS, EPHE, IRD, Montpellier, France \\ 2 Laboratoire Evolution et Diversité Biologique, UMR CNRS 5171, Université Toulouse 3, Paul Sabatier, Toulouse, France \\ 3 Mécanismes adaptatifs et Evolution (MECADEV UMR 7179), Muséum National d'Histoire Naturelle, Centre National de la \\ Recherche Scientifique, Brunoy, France \\ $4 \quad$ Centre de Recherches sur la Biologie des Populations d'Oiseaux (CRBPO), Centre d'Ecologie et des Sciences de la Conservation \\ (CESCO UMR 7204), Muséum National d'Histoire Naturelle, Centre National de la Recherche Scientifique, Sorbonne Université, Bâtiment \\ 135, Paris, France \\ $5 \quad$ Bretagne Vivante, Brest, France \\ $6 \quad$ Univ Brest, CNRS, IRD, Ifremer, LEMAR, Plouzané, France \\ * Corresponding author: se.roques@gmail.com
}

\begin{abstract}
On the journey to wintering sites, most migratory birds alternate between flights and stopovers, where they rest and refuel. In contrast to the time-minimization strategy commonly assumed to drive the pre-breeding migration, birds are rather expected to follow an energy minimization during post-breeding migration. It is the cumulative duration of flights and stopovers that determines the total energy requirements and duration of the journey. Since migrating birds actually spend most of the time at stopovers sites, selection to minimize the amount of energy or time spent on migration is likely to operate on the effectiveness of stopover rest and refueling. Here, we address the relative contribution of factors acting on departure decisions from a stopover site during the post-breeding migration in a long-distance migratory songbird. When capture probability is low, it is impossible to measure fattening over the entire duration of the stopover. To get around this limitation, we use time since arrival (TSA) as a proxy for the progressive temporal change occurring in the internal state of an individual (i.e. rest, physiological recovery, and fuel loading) during the stopover. We develop a capture-recapture model to address the respective effects of estimated TSA and of weather conditions on departure probability. Using a 20year dataset for Sedge Warblers (Acrocephalus schoenobaenus), we show that TSA served as a surrogate of the most important information that birds use when deciding to depart from a stopover site, while low humidity and rising atmospheric pressure only slightly increase daily departure probability. Hence, a bird would resume migration mainly according to the time it had to rest and refuel, and then fine-tuning departure decision according to weather conditions. The generality of these results needs to be assessed by applying this modeling framework to other migratory species and at sites or times with greater weather variability.
\end{abstract}

Keywords: Bayesian inference, capture-recapture, Sedge Warbler, stopover, time since arrival, TSA

\section{LAY SUMMARY}

- During their migratory journey, most migratory birds need to stop at places where they can rest and refuel.

- For migratory birds, most of the time spent in migration is spent at stopover sites. Understanding when and why they decide to leave a stopover site is key to better understanding birds' decisions during migration.

- With 20 years of capture data on the Sedge Warbler (Acrocephalus schoenobaenus) at a stopover site in western Brittany (France), we used capture-recapture models to investigate and quantify the relative influence of time since arrival and weather conditions on departure decision.

- We found that the departure decision is mainly driven by the time an individual has already spent at the stopover site and that humidity and atmospheric pressure variations only have secondary effects on the decision to leave the stopover site.

- Such an approach could be applied to many existing multidecadal datasets to help refining our understanding of birds' stopover ecology.

\section{INTRODUCTION}

Each year migratory bird species commute between breeding and wintering areas (Alerstam 1990, Somveille et al. 2015). Most species cannot go from breeding to wintering grounds in a single flight of thousands of kilometers. They must stop regularly to rest, feed, and refill energy stores regularly (Alerstam 1990, Åkesson and Hedenström 2007, Schmaljohann and Eikenaar 2017). The duration of migratory flights and stopovers determines the energy requirements and also the total duration of the journey (Alerstam 1990, Alerstam and Lindström 1990). To maximize survival, individuals must optimize their journey to match with seasonal variation in food availability (and their energy requirements) at stopover sites and to arrive at wintering areas when resource availability is sufficient (Alerstam 1990, Somveille et al. 2015, 2018, Zúñiga et al. 
2017, Schmaljohann 2018). Birds spend much more time at stopover sites than in migratory flight, with $\sim 85 \%$ of the journey spent on stopover (Hedenström and Alerstam 1997, Green et al. 2002, Schmaljohann et al. 2012). Consequently, selection to minimize the amount of energy spent (energy minimization), the total time spent on migration (time minimization), and the predation risk (predation risk minimization) likely operates mainly on the effectiveness of stopover rest and refueling (Alerstam and Lindström 1990, Hedenström and Alerstam 1997, Lank et al. 2003, Alerstam 2011).

Deciding to leave the stopover site normally means a new flight of hundreds of kilometers. This movement itself, and its termination, are highly constrained by the maximal flight capacity (given the size of energy reserves and body size) and atmospheric conditions (Alerstam 1990, Dänhardt and Lindström 2001, Hake et al. 2003, Jenni and Schaub 2003, Wikelski et al. 2003, Sergio et al. 2014, Schmaljohann and Eikenaar 2017). Once settled at a stopover site, the probability of departing (and the duration of the stay) depends on factors associated with the initiation of movement (i.e. to depart from the site), such as on fuel store, resting state, food availability, weather conditions, and migratory experience (Hake et al. 2003, Jenni and Schaub 2003, Sergio et al. 2014, Schmaljohann and Eikenaar 2017). Recent studies have tried to disentangle the environmental factors driving departure decisions (Schaub et al. 2008, Ktitorov et al. 2010, Arizaga et al. 2011, Deppe et al. 2015, Dossman et al. 2016, Schmaljohann and Eikenaar 2017). Weather conditions are usually considered through the constraint they impose on flight (Richardson 1990, Schaub et al. 2004, Deppe et al. 2015). Departure decisions depend on wind speed and direction (tailwind assistance reduces the cost of flight; Liechti 2006, Tsvey et al. 2007, Arizaga et al. 2011, Ma et al. 2011, Dossman et al. 2016). This decision also depends on rainfall or humidity, which usually forces birds to stay at the stopover site (Schaub et al. 2004, Tsvey et al. 2007, Arizaga et al. 2011, Deppe et al. 2015, Dossman et al. 2016). Cloud cover also influences departure decisions by decreasing visibility and the ability of birds to navigate (Richardson 1991, Zehnder et al. 2001, Åkesson and Hedenström 2007). Last, temperature has also been recently considered as a factor driving departure decisions (Klinner and Schmaljohann 2020).

However, the internal state of the individual (resting state, fuel store, migratory experience) also has a large influence on departure decision: birds need to rest and reach a sufficient level of fuel store to perform the next migratory flight (Alerstam 1990, Hedenström and Alerstam 1997, Schaub et al. 2008, Goymann et al. 2010, Dossman et al. 2016, Moore et al. 2017, Schmaljohann and Eikenaar 2017, Anderson et al. 2019). Apart from resting to recover from extreme physical exercise and sleeping to recover from sleep deprivation during migratory flight (Schwilch et al. 2002), birds at stopover sites allocate most of their time and energy to foraging (Hedenström and Alerstam 1997, Cohen et al. 2014, Smith and McWilliams 2014). They are assumed to refill their energy stores as fast as possible and to continue their migratory journey when their energy stores and weather conditions are favorable (Péron et al. 2007, Eikenaar and Schläfke 2013, Schmaljohann and Eikenaar 2017). In addition, the ability to refuel and rest may depend on age or experience, which can lead individuals migrating for the first time (juveniles) and those that have already traveled to wintering areas in the past (adults) to depart from stopover sites after stays of different durations or under different weather conditions (Deppe et al. 2015, Dossman et al. 2016).

To our knowledge, the relative importance of the internal state of individuals (resting state, fuel store) and prevailing weather conditions in determining departure probability has never been quantified using a long-term dataset within a single capture-recapture (CR) modeling framework. The conflicting results of previous studies concerning the relationship between fuel store and departure probability could be due to different local constraints or to the different migration strategies (time vs. energy-minimizing; Hedenström and Alerstam 1997, Schmaljohann 2018, Anderson et al. 2019, Packmor et al. 2020). More importantly, differing results could be due to the fact that, unless baited electronic balances are used (Schmaljohann et al. 2013) or birds are maintained in captivity (Eikenaar and Schläfke 2013), fuel store can only be measured when individuals are physically captured. In addition, when capture occurs, this is not necessarily at the very beginning and end of the bird's stopover. The lack of effect of fuel store on departure probability could also arise because the method to jointly incorporate internal individual state and environmental covariates in the same CR framework was not available (Jenni and Schaub 2003, Schmaljohann and Eikenaar 2017). Here, we define and estimate a variable that can otherwise only be measured using telemetry devices: the time the individual has spent at the stopover site since its arrival: time since arrival (TSA; Pledger et al. 2008). Our goal is to assess the influence of TSA on departure probability using a long-term dataset created when electronic devices did not exist yet and to include a large number of individuals and years in the analysis. Despite limitations of retrospective analyses of long-term datasets (when modern electronic techniques were not available), such datasets offer interesting opportunities: (1) large sample sizes to draw robust and general inference about departure probability using statistical approaches and (2) long time series of observations to characterize long-term patterns and yearly deviations from deep-rooted trends. Birds need to rest after a long-distance migratory flight. Their energy stores increase rather linearly with the duration of the stay at the stopover site, up to a threshold constrained by the maximal fattening ability of the individual (Alerstam 1990, Schwilch and Jenni 2001, Jenni and Schaub 2003, Rguibi-Idrissi et al. 2003, Péron et al. 2007, Schaub et al. 2008, Schmaljohann and Eikenaar 2017). Our premise is that TSA is an integrative proxy for the overall change occurring in the internal state of a bird during its stopover. Over a number of days, birds accumulate compensatory rest and feeding, and 
they progressively rebuild their fat stores and muscle mass (Alerstam 1990, Jenni and Schaub 2003, Schmaljohann and Eikenaar 2017). In this framework, we expect a positive relationship between departure probability and TSA, and TSA to be a major determinant of departure probability. Importantly, TSA must be estimated using an analytical technique accounting for the daily capture probability of marked individuals (i.e. the probability of capturing an individual that is alive and present in the site). This is a methodological challenge because investigators know neither the day when a bird arrives nor the day when it departs from the site. Many CR stopover studies have relied on the assumption that birds are captured for the first and last time on the exact days of arrival and departure from the site (Schmaljohann and Eikenaar 2017). This assumption is unrealistic: at songbirds' stopover sites, the probability that an individual is captured in a given day is usually low and often lies between 0.1 and 0.2 (Schaub and Jenni 1999, Schaub et al. 2001, Moore et al. 2017), and the resulting "minimal stopover duration" (duration between first and last captures) strongly underestimates the actual stopover duration (SOD) (by a factor that may be as large as 3; Schaub et al. 2001). Estimating TSA requires the development of a statistical model accounting for imperfect detection probability.

Here, we evaluate the contribution of estimated TSA and weather conditions to departure probability. We develop a CR model and analyze a long-term CR dataset from a long-distance migrant songbird at a stopover site. Because improving its internal state through refueling, recovering, and sleeping seems to be the major biological function of stopover (Schmaljohann and Eikenaar 2017, Schmaljohann 2018, Eikenaar et al. 2020a, 2020b, Klinner et al. 2020, Linscott and Senner 2021), we expect that TSA will be the main driver of departure probability in this longdistance migrant and that wind, humidity, cloud cover, and atmospheric pressure will have a secondary but significant effect on departure probability (Packmor et al. 2020). Estimated TSA should be closer to the genuine duration of the individual's stay than the time elapsed between the first and the last physical captures of the individual. If TSA integrates the overall changes in the individual internal state, this should help us detect the effect of stay duration on departure probability, if any. Moreover, we also expect that SOD will differ according to migratory experience, as documented in other studies (Deppe et al. 2015, Mitchell et al. 2015), and we test for differences between juveniles and adults.

\section{MATERIAL AND METHODS}

\section{Study Area, Sampling, and Dataset}

The study site is the Trunvel ringing station (Tréogat, Brittany, France; $47.8960^{\circ} \mathrm{N}, 4.3618^{\circ} \mathrm{W}$ ). The site is located close to the shore on one of the most westerly coasts of Brittany, and there is no apparent ecological barrier around for songbirds on their way south. The site consists mainly of a large reedbed area where food resource availability is high. Data from marked individuals have been collected using a standardized mist-netting protocol (including tape-luring; Bargain et al. 2002). Each captured bird was identified, ringed, and aged. We used data collected from 1990 to 2014, from the 1st to the 30th of August because $90 \%$ of the captures occur in this month. The years when the number of recaptures was too low $(1991,1992,1998$, 1999, and 2000) were not used in analyses ( $<10$ birds recaptured only once). The Sedge Warbler (Acrocephalus schoenobaenus) is the most abundant species that stops over at this site during its journey to winter quarters in sub-Saharan Africa. This 12-g songbird strictly depends on reedbeds where it essentially forages on one aphid species (Hyalopterus pruni) to refill energy stores (Bibby and Green 1981).

Between 1990 and 2014, 79,700 individuals have been marked (Dehorter and CRBPO 2015). Among all migrant songbirds that use this site, only a small fraction stays several days to rest and refuel (i.e. actual stopover; Warnock 2010). The majority either continue migration by the following night or move to another stopover place (i.e. transients; Bächler and Schaub 2007, Schaub et al. 2008). As we aim to study the departure probability of birds that stayed over at the site, we filtered our records to include only CR data from birds that were caught at least twice during a season, prior to summarizing the capture histories on a daily basis (the data include recaptures occurring during the same day). Hence, the estimated SOD applies only to the part of the population passing by the site and that stays for at least some hours or days. This filtering criterion may have selected birds with a higher-than-average detection probability. However, preliminary analyses did not support this hypothesis: the capture probability of first capture (marking) and on the day of arrival was not higher than during subsequent occasions. This suggests that removed individuals captured only once are much likelier to be transients and that our filtering criterion may not have selected birds with a higher-than-average detection probability. Finally, the sample we used is of 683 adults and 4,927 juveniles; their latest recapture occurred at the site, on average, $3.4 \pm 3.6$ (mean \pm standard deviation [SD]) days after their first capture. The mean mass gain between first and last capture on individuals was $0.48 \pm 1.48 \mathrm{~g}$ (mean \pm $\mathrm{SD})$. 


\section{Weather Conditions}

Weather variables expected to influence daily departure probability (between day $t-1$ and $t$ ) were (1) wind (on day $t-1$ ), (2) relative humidity (on day $t-1$ ), (3) cloud cover during the night (i.e. between day $t-1$ and $t$ or sunset at day $t-1$ to 3 hr before sunrise at day $t$; scale from 0 [no cloud] to 8 [complete sky cover]), and (4) atmospheric pressure; as birds likely perceive changes in pressure rather than pressure itself, we used the change in atmospheric pressure between day $t$ and day $t$ - 1 as a covariate (denoted as $\Delta$ Pressure in $\mathrm{hPa}$, as in Deppe et al. 2015; in preliminary analyses, changes in atmospheric pressure over longer time scales [i.e. day $t-2$ and day $t-3$ ] proved to be less influential and were not considered further; results not shown). Depending on its direction, wind can either facilitate flight (tailwind) or increase the cost of flight (headwind). To integrate both wind effects, we computed the wind covariate as in Arizaga et al. (2011):

wind $=\operatorname{Vcos}\left[\alpha_{T}-\left(180^{\circ}+\alpha_{W}\right)\right]$,

where $V$ is wind speed $\left(\mathrm{m} \mathrm{s}^{-1}\right), \alpha_{T}$ is the assumed departure direction $\left(120^{\circ}\right.$ according to recovery data; note that birds do not cross the Bay of Biscay, Dehorter and CRBPO 2015, so $120^{\circ}$ is almost the coast direction), and $\alpha w$ is the direction of the wind (Akesson et al. 2002). Because Sedge Warblers tend to depart on migration during the first hours after sunset (Müller et al. 2018), we used wind speed and direction observed during a period of time starting $2 \mathrm{hr}$ before sunset on day $t-1$ and ending in the middle of the night on day $t$. All weather covariates were scaled prior to the analyses. The weather data were provided by the Penmarch meteorological station $(47.797537,-4.374768)$.

\section{Modeling and Statistical Analyses}

We used a formulation of the Jolly-Seber (JS) model (Jolly 1965, Seber 1965) parameterized with entry probability in the sampling area (Crosbie and Manly 1985, Schwarz and Arnason 1996). This allows modeling the arrival of birds at the stopover site and estimating SOD (Lyons et al. 2016, Lok et al. 2019, Roques et al. 2021). The parameters of the model are as follows: $\phi_{t}$ is the probability of staying in the sampling area from day $t$ to $t+1 ; \eta_{t}$ is the probability of arriving at the stopover area on day $t$ given that the individual was not present in the site before; and $p_{t}$ is the probability of capturing the individual on day $t$ given that the individual has arrived and has not yet left the site.

We used the Bayesian, state-space formulation of the JS model (Gimenez et al. 2007, Royle 2008). This model contains a submodel for the state process: true, partially unobservable states are "not yet arrived," "present in the study area," and "departed." The model also includes a submodel for the observations (conditional on the true state) directly encoded in the individual capture histories. For each individual capture history $h_{i}$, the true state history is accounted for by the vector $z_{i}$. This vector of binary state variables describes if an individual $i$ is present in the stopover area on day $t, z_{i, t}=1$, or not, $z_{i, t}=0$.

The state process is defined as:

$$
z_{i, t} \mid z_{i, t-1} \sim \text { Bernoulli }\left(\phi_{t-1} z_{i, t-1}+\eta_{t} \prod_{j=1}^{t-1}\left(1-z_{i, j}\right)\right)
$$

The term $\prod_{j=1}^{t-1}\left(1-z_{i, j}\right)$ term accounts for the availability of the individual to enter the stopover area and is equal to 1 when the individual has not yet entered the stopover area, and 0 when it has already entered. This equation formalizes the following process: a bird can be present in the study area at day $t$, either because it was already present the previous day $(t-1)$ and has not left the stopover site $\left(\varphi_{t-1}\right)$, or because it arrived at day $t$ at the stopover site with probability $\eta_{t}$.

As the binary observations are conditionally independent Bernoulli random variables, the link between the state and observation processes is given by the following equation:

$$
h_{i, t} \mid z i, t \sim \text { Bernoulli }\left(z i, t, p_{t}\right)
$$

This means that if individual $i$ has not yet entered the stopover area or has left $(z i, t=0)$, then $h_{i, t}=0$ with probability equal to 1. If $z i, t=1$, then the capture history $h_{i, t}$ is a Bernoulli trial with probability $p_{t}$, which is the probability of capturing the individual on day $t$. This equation accounts for the imperfect detection of individuals. This formulation of the model allows us to estimate TSA for each individual. The TSA covariate is a partially or non-observable variable computed using the sum of true states $z i, t$. TSA accounts for the time individual $i$ has already spent in the stopover area on day $t$ : 


$$
T S A_{i, t}=\sum_{s=1}^{t-1} z_{i, s}
$$

The state vector $z_{i}$. also allows us to use a new formulation of the SOD described in Lyons et al. (2016). We computed the mean SOD (in days) as follows:

$$
S O D=\frac{\Sigma_{i} \Sigma_{t} z_{i, t}}{n}
$$

where $n$ is the number of individuals and $z$ is the true state variable (whether individual $i$ was present or not at the stopover site on day $t$ ). In other words, SOD is estimated as the number of bird-days divided by number of individual birds.

Insufficient data availability prevented the estimation of a separate capture probability for each day (in some days, there are only 1 or 2 captured birds). The most parsimonious option to account for heterogeneity in detection probability among capture occasions was to model detection probability as a normally distributed random effect over all capture occasions. Thus, we modeled the capture probability during year $y$ at time $t$ as:

$$
\operatorname{logit}\left(p_{y, t}\right) \sim \operatorname{Norm}\left(\operatorname{logit}\left(\mu_{p}\right), \sigma_{p}\right) \text {, }
$$

where $\mu_{p}$, is the mean and $\sigma_{p}$ is the SD of the random effect. The exception is for days with no capture attempt (e.g., too rainy or windy), for which capture probability was fixed to zero in the model.

We expressed the probability of remaining at the site as a function of the previously defined weather covariates and TSA. We considered effects as "statistically significant" when the estimated slope corresponding to these covariates had a $95 \%$ credible interval (CI) excluding 0 (Kéry and Schaub 2011). We analyzed the 20 years of data simultaneously, but accounted for potential differences among years (Péron et al. 2007) by means of a random year effect, where $y$ is the number of the year:

$$
\text { Yeary } \sim \text { Norm (Hyear, Oyear) }
$$

To account for the effect of the experience on an individual's departure probability from the stopover site, we used agedependent random effects with 2 age classes (Adult and Juvenile), where $a$ is the age class:

$$
\text { Age } a \sim \operatorname{Norm}(\mu \text { Age, } \sigma \text { Age })
$$

During preliminary analyses, we did not model the effect of age (Age $\left.{ }_{a}\right)$ on departure probability. However, when we simply plotted SOD per age category (as in Figure 1) using the estimates of departure probability from each individual, the difference between juveniles and adults was already present (and consistent with Figure 1). Thus, the difference between adults and juveniles shown in results is not virtually induced by the inclusion of the age effect.

Using a logit link, the probability of staying at the stopover area between $t-1$ and $t$ was formulated as:

$$
\begin{aligned}
\operatorname{Logit}\left(\phi_{i, t-1}\right)= & \alpha+\beta_{1} * T_{S A} A_{i, t-1}+\beta_{2} * \text { wind }_{t-1}+\beta_{3} * \text { temperature }_{t-1}+\beta_{4} * \text { cloudcover }_{t-1}+\beta_{5} \\
& * \text { humidity }_{t-1}+\beta_{6} * \Delta \text { Pressure }+ \text { Year }_{y}+\text { Age }_{a}
\end{aligned}
$$

Here. we included all the covariates in the model despite a non-null collinearity between most of the environmental covariates (see Supplementary Material Tables S2 and S3 for details). However, this collinearity was sufficiently small ( $<0.3$ for most of the covariates) to allow the inclusion of all effects in a same model (Hair et al. 2006). Usually, a correlation coefficient greater than 0.7 or 0.8 is considered as problematic (Hair et al. 2006). Moreover, to ensure that this weak collinearity does not affect our conclusions, we ran models with only one environmental covariate at a time to check whether or not the estimated effect was the same. The results confirmed our hypotheses that all covariates can be included in the same model without compromising the robustness of our conclusions (based on the comparison of parameters' estimates in Table 1 and Supplementary Material Table S3). Also, because TSA is computed at each occasion for each individual, TSA cannot be standardized prior to analyses. To compare the effect of TSA on departure probability to that of weather covariates, we calculated the effect of a standardized TSA by multiplying the estimated values of the TSA slopes $\left(\beta_{1}\right)$ by the SD of all estimated TSA values. Although interactive effects may make sense (e.g., the longer TSA, the higher the effect of weather, or age-dependency of covariates' effects), given the limited amount of information contained in our CR dataset, considering only the additive effects of explanatory variables was the best option to achieve a reasonable tradeoff between model realism and robustness of inferences (significance and precision).

We performed analyses with JAGS (with the package R2jags; Hornik et al. 2003, Su et al. 2015) using R 3.6.1 (R Development Core Team 3.0.1. 2013). We used 60,000 iterations with a burnin of 30,000, and we checked chain mixing and convergence (Kéry and Schaub 2011). The JAGS code is available in the Supplementary Material. 
FIGURE 1. Between-year variation in individual SOD estimates (in days) per age category for Sedge Warbler (Acrocephalus schoenobaenus).

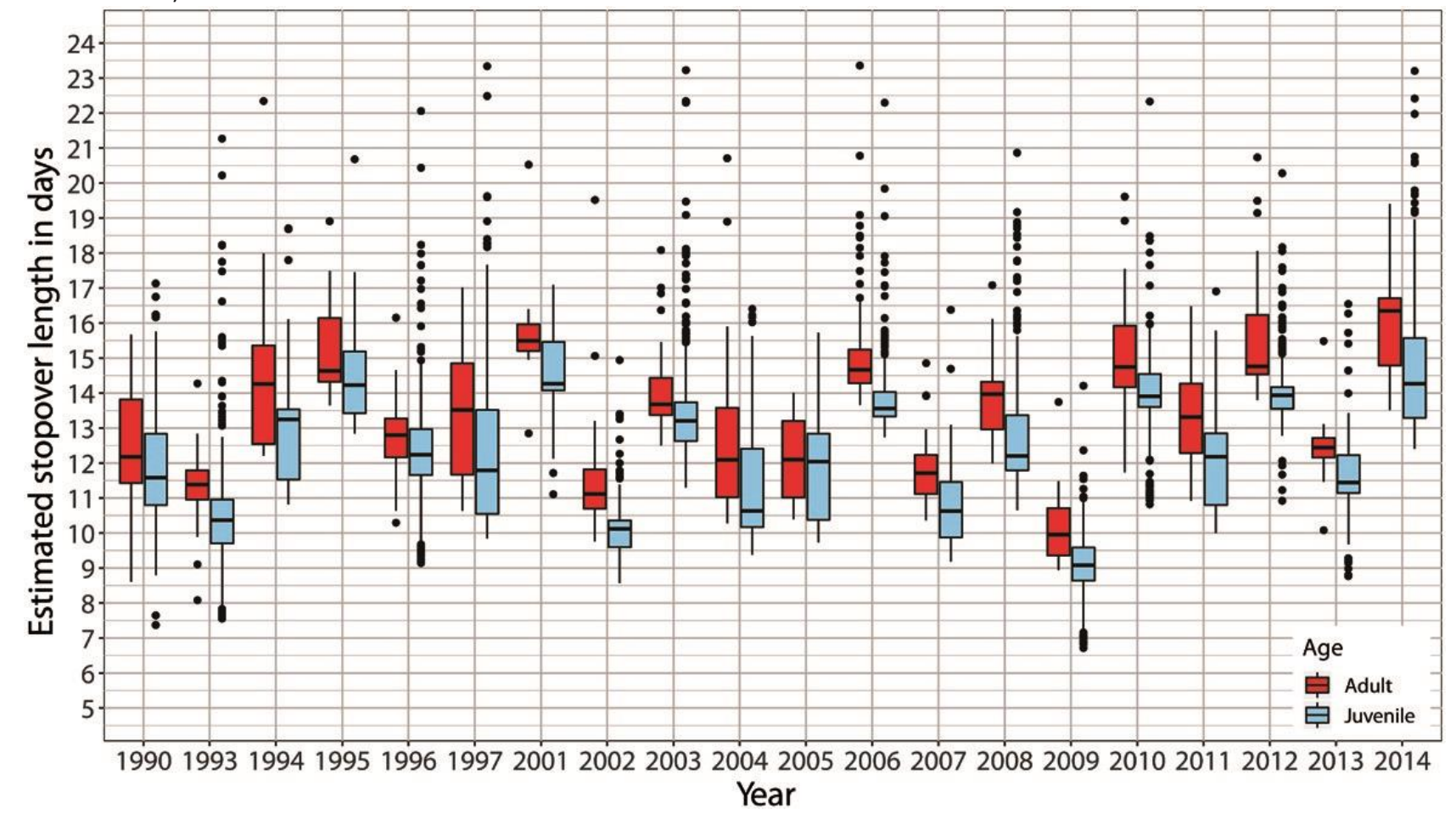

TABLE 1. Estimated effects of covariates on the probability of staying at the stopover area: mean value, SD, and Cls. Bold: significant effects.

\begin{tabular}{lrlc}
\hline & Mean & SD & \multicolumn{1}{c}{ Cls } \\
\hline$(\alpha)$ Intercept & 6.159 & 0.175 & $5.843,6.578$ \\
$\left(\beta_{1}\right)$ TSA & $\mathbf{- 1 . 5 3 8}$ & $\mathbf{0 . 0 3 9}$ & $\mathbf{- 1 . 6 5 2 , - 1 . 4 3 2}$ \\
$\left(\beta_{2}\right)$ Wind & 0.116 & 0.1 & $-0.121,0.196$ \\
$\left(\beta_{3}\right)$ Temperature & -0.207 & 0.89 & $-0.387,0.03$ \\
$\left(\beta_{4}\right)$ Cloud cover & 0.142 & 0.101 & $-0.052,0.207$ \\
$\left(\beta_{5}\right)$ Humidity & $\mathbf{0 . 4 9 7}$ & $\mathbf{0 . 1 2 1}$ & $\mathbf{0 . 2 6 1 , 0 . 7 3 5}$ \\
$\left(\boldsymbol{\beta}_{6}\right) \Delta$ Pressure & $\mathbf{- 0 . 7 0 2}$ & $\mathbf{0 . 2 3}$ & $\mathbf{- 1 . 1 7 6 , - 0 . 1 9 6}$ \\
\hline
\end{tabular}



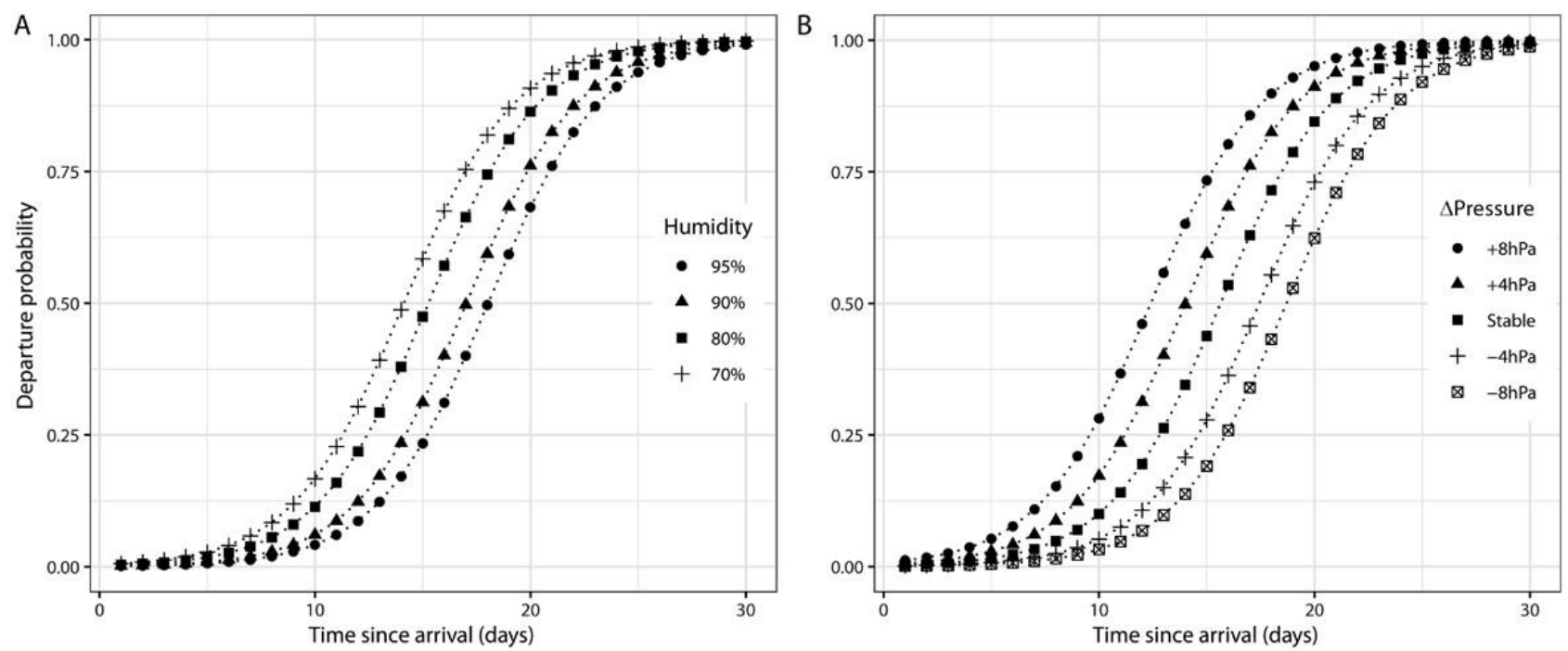

FIGURE 2. Departure probability as a function of the number of days since the bird arrived. (A) Humidity conditions ranging from $70 \%$ to 95\%. (B) Different $\triangle$ Pressure conditions: from an increase of $8 \mathrm{hPa}$ to a decrease of $8 \mathrm{hPa}$.

\section{RESULTS}

The mean estimated SOD for the whole study period is $12.5 \pm 2.2$ days CIs [12.2; 12.8], with unstructured variation among years (Figure 1). Adults (experienced birds) stay on average 1.6 days more than juveniles (naive birds) (13.8 \pm 2.2 for adults and $12.2 \pm 2.1$ days for juveniles). This age difference is robust through years (Figure 1). However, the $95 \%$ CIs and SD of estimated SOD for juveniles and adults overlap (Figure 1). Thus, age accounts for a very limited part of the SOD variation between individuals.

Departure probability from the stopover site between 2 days $\left(1-\phi_{t}\right.$, i.e. the complement of the probability of staying at the stopover site) is positively related to TSA (Figure 2). In other words, the longer a bird has already stayed at the site, the higher is its probability of resuming migration flight by the following night. TSA is the most important predictor of departure probability compared with other variables, based on effect sizes (Table 1). TSA effect is also the effect that is estimated with the largest precision, which suggests a small variability of the TSA effect among individuals (see CIs in Table 1).

Both humidity and $\Delta$ Pressure had an effect on the departure probability from the stopover site (Table 1). Departure probability increases with drier conditions and large positive changes in pressure ( $\Delta$ Pressure). We did not find evidence of an effect of wind on departure probability (Table 1). We found slight evidence of a negative effect of cloud cover on the departure probability from the stopover site (Table 1), but the robustness of this result is weak because one boundary of the $\mathrm{CI}$ overlaps 0. Estimates of TSA and humidity effects on departure probability (Figure 2A) or of $\triangle$ Pressure effect (Figure 2B) show that departure probability primarily depends on TSA (with the larger effect value), and that $\Delta$ Pressure and then humidity are the second and the third covariates, respectively, determining departure probability.

The signs and values for parameter estimates for the effects of weather covariates, and their estimated CIs (Table 1), were robust to the moderate correlations among our weather covariates (Supplementary Material Table S1), as indicated by the qualitatively identical and numerically similar estimates of the effects of weather that we found when each of the weather variables was fitted separately (Supplementary Material Table S3).

\section{DISCUSSION}

Effect of the TSA on Departure Probability Our statistical framework to address covariates' influencing the probability of leaving a stopover site allowed us to provide evidence that TSA is the major determinant of this probability for the Sedge Warbler at our study area. TSA is a reliable indicator of the propensity of an individual to leave the stopover site. We acknowledge that TSA is only a proxy of all the changes in the individual "state" (sensu Clark and Mangel 2000) during the stopover, but it is reasonable to think that TSA reflects the progressive change in the individual internal state. On the first 
day after arrival, birds are supposed to be exhausted, starving, and to lack fuel stores. The longer they stay, the more opportunities they have to rest, feed, fatten, and restore their pectoral muscles (Schmaljohann and Eikenaar 2017).

TSA encompasses different functions of the stopover behavior: (1) resting after a migratory flight with the associated physiological processes (McWilliams et al. 2004, Skrip et al. 2015, Eikenaar et al. 2020a, 2020b) and (2) reaching a sufficient level of fuel load to perform the following migratory flight (Schmaljohann and Eikenaar 2017). TSA also reflects (3) the refueling rate, which depends on environmental conditions and physiological processes (Jenni and Schaub 2003, Schmaljohann and Eikenaar 2017, Eikenaar et al. 2020a, Linscott and Senner 2021). Here, TSA has a positive effect on departure probability: birds need to stay a minimum number of days before leaving (virtually no departure is predicted during the very first days; see Figure 2). For birds that do increase in body mass, the fuel storage (fat deposition, muscle rebuilding) increases through time: the longer an individual stays at stopover, the larger their last measured body mass or fuel load (mean mass gain of $0.48 \mathrm{~g}$ between first and last capture in the present study; Alerstam 1990, Schmaljohann and Eikenaar 2017) and the larger the daily mass gain (Rguibi-Idrissi et al. 2003, Péron et al. 2007). Consequently, it is reasonable to think that birds need to rebuild a sufficient level of fuel store to perform another migratory flight (Alerstam 1990). Moreover, the resting time after a long migratory flight is apparently brief and confined to the first hours or days of the stopover (Fuchs et al. 2006, 2009; Németh 2009). This suggests that resting is not the physiological process that requires a 12-day stopover. Rather, most of the time spent in stopover is allocated to foraging in order to refill energy reserves; the latter is a long and progressive process. Hence, for the fraction of birds that stopover at this place, we believe that TSA reflects the time required by the physiological processes involved in refueling (Schmaljohann and Eikenaar 2017, Eikenaar et al. 2020a, 2020b). Determining the precise relationship between TSA and fuel store will be an important area of future research in stopover ecology and more specifically for the application of the present modeling framework.

Traditional measures of fuel store such as size-scaled body mass, fat scores, or muscle scores have some limitations (Schwilch and Jenni 2001, Schmaljohann and Eikenaar 2017), of which we want to highlight two. (1) In many long-term migration monitoring programs of marked birds, especially in old datasets, body mass was not systematically recorded at each recapture event. This drastically reduces the sample size available for long-term analyses where we need a body mass measurement at each recapture. In the French dataset for the Sedge Warbler, in the 20th century, individuals were weighed on only 60\% of the capture events (Dehorter and CRBPO 2015). Presently (2000-2016 period), individuals are weighed on nearly all the capture events (90\%). (2) Because the probability of being captured in a given day can be low in routine trapping protocols (0.161 [0.058, 0.376] in this study; Schaub et al. 2001, Schmaljohann and Eikenaar 2017), the body mass measured at the latest capture is unlikely to be representative of the body mass that actually triggers departure. Imperfect detection probability is a common situation where modeling the individual history before the first capture is required to estimate arrival date. This imprecision in the assessment of the body mass change through time can mask the effect of body mass on departure probability in datasets where daily capture probability is low. Overall, the proposed analytical method, relying on TSA, allows analyzing individual variations in SOD over long time series, even in the absence of biometric data, and even when body mass or fat score information is too sparse to reliably document the progress through time of the energetic state of each monitored individual.

Using TSA as a proxy for the internal state of the bird just before departure requires some critical assumptions. When birds stay only few days, they may not improve the condition with time spent at the stopover site because they may first continue to degrade upon arrival waiting for their digestive system to redevelop to refuel after a long-distance migratory flight (McWilliams et al. 2004). To overcome this situation, further research on the refueling process during stopover may be helpful to better model the TSA effect. The relevance of TSA may also be limited when birds relocate in the vicinity of the study site (Bächler and Schaub 2007): in this case, the departure from the study site does not mean that individuals are resuming a long-distance migratory flight. Birds relocating a few kilometers away from the study site do not need to wait until their internal state improves before leaving the site. To get around these problems, birds captured only once are usually removed from CR datasets. This removes most of the transient individuals (Mills et al. 2011, Taylor et al. 2011, Sjöberg et al. 2015). If data from individual condition are available and with technical developments allowing investigators to easily use individual continuous covariates in stopover CR models, including both estimated TSA and fuel store data (body mass, fat score, and muscle score) in a model would be an interesting avenue to revisit previous analyses. This will help us to understand the contrasted results of previous studies about fuel store effects on departure probability (Tsvey et al. 2007, Schaub et al. 2008, Arizaga et al. 2011, Smith and McWilliams 2014, Schmaljohann and Eikenaar 2017).

Also, other limitations, more related to modeling and data, appear when we use this type of model. A large number of recaptures are required to test for more precise and potentially more complex effects of the various determinants of departure probability. For example, interactions between TSA and date, age, or weather conditions could have been considered. However, correctly estimating such interactions could have constrained us to drastically reduce the dataset and keep only individuals captured at least 3 times, which does not occur in some years in our dataset. These would be interesting avenues 
to investigate with datasets with a higher detection probability, for example with capture-mark-resight shorebirds datasets (Lok et al. 2019). Also, we would like to emphasize that the logit linear relationship between probability of departure and TSA is a particularly adapted parsimonious description of the phenomenon of departure from a stopover site. Indeed, it is expected that departure is virtually impossible in the first days after arrival when birds need to rest and replenish their fuel load; then, it increases rapidly during the range of days when individuals progressively reach the level of body condition that allows them to resume migration (this is when weather conditions are expected to have the maximum effect). Eventually, the urge to depart and a high body condition will push them to depart in all but extreme weather conditions. These stages are well rendered by the logit linear relationship (see Figure 2). Last, here we define a general framework to understand the effect of TSA on departure probability, but all the processes described above may vary in intensity and speed among individuals (e.g., early vs. late migrants; Bayly 2007) and also among years. Investigation of the sources of heterogeneity in the TSA effect on departure probability among individuals and years is a promising research avenue for stopover ecology.

\section{Effect of Weather Conditions on Departure Probability}

On relatively humid days, birds tend to postpone departure (Erni et al. 2002, Schaub et al. 2004). Birds wait for dryer conditions to resume their migratory flight. Humidity can be high even in the absence of precipitation in Western Brittany. The negative effect of high humidity can reflect not only the inhibitory effect of rain but also the degraded flight conditions during foggy or cloudy nights (Åkesson et al. 2001, Deppe et al. 2015). The probability of departing from the stopover site increases when atmospheric pressure increases between the day before the night of departure and from 2 days before. Increasing air pressure is likely indicative of improving flight and navigation conditions with better visibility (clear sky) and reduced risk of precipitations (similar to the positive effect of decreasing air humidity in Deppe et al. 2015). Unexpectedly, departure probability does not depend on wind, probably because wind was too rare and weak in the study area in August to be influential (mean wind force during the study period was $5 \mathrm{~m} \mathrm{~s}^{-1}$; see Supplementary Material Table S2 for a summary of the weather covariates). Finally, we did not find evidence of an effect of 3 out of 5 weather covariates (temperature, cloud cover, and wind) on departure probability at this stopover place. This could be due to the generally stable conditions at this place in August and to the absence of ecological barriers to cross in the vicinity of the site. It would be interesting to conduct similar analyses at a stopover place further south, close to a large ecological barrier: the Pyrenees (Fontanilles et al. 2020).

\section{Effect of Migratory Experience on Departure Probability}

Juveniles (birds migrating for the first time) stay on average 1.6 days (11.6\%) less than the older, more experienced birds at the stopover area. Even though age accounts for a limited variation in SOD in our study, this result is consistent with former studies that have shown that juvenile and experienced birds behave differently regarding departure probability from stopover sites: juveniles make shorter and more frequent stopovers than adults (Reilly and Reilly 2009, McKinnon et al. 2014). However, other studies reached opposite conclusions: telemetry studies of departure decisions in songbirds in the Gulf of Mexico during autumn did not find any effect of age on the decision to cross the Gulf of Mexico or of the selection of weather conditions (McKinnon et al. 2014, Deppe et al. 2015). Globally, there is no consensus about the age effect on stopover strategy (Hake et al. 2003, Moore et al. 2017), and the strategy may depend on many different factors such as the selection of weather conditions for departure (Mitchell et al. 2015). Again, it is legitimate to ask whether imperfect detection probability is involved in inconsistencies among studies concerning the relationship between age and departure probability from stopover sites.

\section{Respective Effects of TSA and Weather Conditions on Departure Probability}

In this study, we show that the contribution of TSA to departure probability in a long-distance migrant is larger than that of weather conditions. This suggests that even when weather conditions are favorable to departure, birds need to stay a minimum amount of time before departing. To our knowledge, this is the first time that the contributions of these factors were estimated with a CR model. Nevertheless, our result is consistent with numerous studies that have highlighted the key role of the improvement of the individual internal state (fuel store, fuel deposition rate, body condition, body mass, and resting) on departure decisions from a stopover site (see Schmaljohann and Eikenaar 2017 for a review and Anderson et al. 2019 for a recent study with telemetry tools).

The improvement of the internal state during a stopover could be indirectly related to environmental conditions. Indeed, harsh weather can decrease the ability of individuals to feed and limit food availability (i.e. reduced invertebrate production and activity). This likely leads to a decrease in the rate at which birds accumulate energy (Jenni and Schaub 2003). If this holds, weather conditions can affect the effect of TSA on departure decisions. Interestingly, here, we found slight evidence of an effect of weather conditions on departure probability when TSA was also taken into account in the analysis. This hierarchy between TSA and weather conditions could also be due to the stability of the weather conditions in August at this 
stopover site: weather conditions cannot be the most important factor determining departure probability if they are generally stable. At a site with more variable weather conditions, TSA might not be predominant. The relationship between TSA and weather conditions during the stopover should be addressed in future work to better understand the processes involved in departure decisions from stopover sites.

Recent studies also highlighted that migration distance affects the stopover strategy of birds (Anderson et al. 2019) and that birds also behave differently in stopover sites along their journey (Schmaljohann et al. 2017). Concerning the Sedge Warbler at our studied site, individuals do not come from a specific origin (recaptures involved birds from Great Britain, Scandinavia, and Eastern Europe; Dehorter and CRBPO 2015) and do not have a specific final destination (Western Africa). However, as we study only one species which is a strictly trans-Saharan migrant, the variability of stopover strategy induced by migration distance could be limited. For long-distance migrants such as the Sedge Warbler, the fact that the effect of TSA dominates over the effect of weather conditions at a stopover site suggests that birds follow a time-minimizing strategy (Hedenström and Alerstam 1997, Bayly 2006, Packmor et al. 2020). However, our mean SOD appears long enough to suggest that motivations or processes other than rapid refueling are involved at our site (as discussed above). Bayly's (2007) results suggest that some Sedge Warblers do refuel rapidly, whereas others refuel at a slower pace at stopover places in Northwestern Europe. He also suggests that this duality in fueling behavior is induced by the Sedge Warbler perception of aphid abundances along the migration route: early migrants are supposed to find higher aphid abundances further south, whereas later migrants will encounter the best conditions for fuel storage in northwestern Europe (Bibby and Green 1981, Bayly 2007). As our stopover site is located only $500 \mathrm{~km}$ south-west to the one studied in Bayly (2007), these 2 fueling behaviors may also coexist in our sample. Moreover, as in Bayly (2007), we did not find evidence of an effect of wind on departure probability. Hence, the long mean SOD estimated here and the weak sensitivity to weather conditions could reflect the plasticity in the expression of migration strategies at different stopover places along the migration route (Schmaljohann et al. 2017, ShamounBaranes et al. 2017). As suggested by Bayly (2007), plasticity could make it difficult to assign Sedge Warblers to a specific strategy. Finally, as in Schmaljohann et al. (2017), the flexible reactions of Sedge Warblers at stopover sites along their migration route should be studied to better understand the drivers of the departure decision at each stopover site, and how the different migration strategies are expressed throughout their annual migration cycle.

\section{Conclusions}

We incorporated TSA, a partially hidden individual state, and weather conditions in the same CR modeling framework to disentangle the factors playing a part in the decision to depart from a stopover site. Using a long-term dataset, we showed that TSA is the main driver of departure probability in a long-distance migrant songbird. This approach will allow investigation of the determinants of SOD and departure probability (not only weather variables but also some hidden physiological processes accounted for by TSA) in hundreds of existing long-term datasets, where there is no, or scattered information about mass or fat score. We demonstrated the feasibility and relevance of this analytical approach using data from one site, one species, and over a long period of time. Our modeling approach will have to be used with data from several species, at several sites, to assess the robustness and generality of our conclusion about the major influence of TSA as a proxy for the internal state reached by an individual on the time when it decides to leave its stopover site.

TSA also has broader implications outside migration ecology in situations where the time individuals spend on sites is a partially observable variable. For example, in behavioral ecology and foraging ecology, the probability of an individual changing foraging site could also depend on the time spent in a site, the number of competitors, or food availability. TSA opens large perspectives when behavior depends on the time spent in a site, in a specific state, and when detection probability is imperfect at the time scale relevant to the research topic addressed.

\section{SUPPLEMENTARY MATERIAL}

Supplementary material is available at Ornithology online.

\section{ACKNOWLEDGMENTS}

This study was made possible, thanks to tens of bird ringers and hundreds of assistants who volunteered in this long-term monitoring over 3 decades and the continued support of the Société d'Etude de la Protection et de la Nature de Bretagne/ Bretagne Vivante. This study was supervised by the Centre de Recherches sur la Biologie des Populations d'Oiseaux (CRBPO), the Museum National $\mathrm{d}^{\prime}$ Histoire Naturelle, the CNRS, and the Ministère de l'Environnement. We thank two anonymous reviewers and journal editors for their helpful comments. 
Funding statement: E.C. was supported by the French

Laboratory of Excellence project "TULIP" (ANR-10LABX-41; ANR-11-IDEX-0002-02).

Ethics statement: This work was carried out in accordance with standard animal care protocols approved by the CRBPO. Author contributions: S.R. carried out modeling and statistical analyses, wrote the manuscript, and participated in the design of the study; P.-Y.H. helped to design the study and critically revised the manuscript; B.B. and G.G. collected data and revised the manuscript; E.C. critically revised the manuscript; and R.P. designed the study, participated in the statistical modeling, and critically revised the manuscript.

Data availability: Data used to conduct the analyses are available at https://github.com/sebroques/Article_Sedge_warbler

\section{LITERATURE CITED}

Åkesson, S., and A. Hedenström (2007). How migrants get there: Migratory performance and orientation. BioScience 57:123-133.

Åkesson, S., G. Walinder, L. Karlsson, and S. Ehnbom (2001). Reed warbler orientation: Initiation of nocturnal migratory flights in relation to visibility of celestial cues at dusk. Animal Behaviour 61:181-189.

Åkesson, S., G. Walinder, L. Karlsson, and S. Ehnbom (2002). Nocturnal migratory flight initiation in reed warblers Acrocephalus scirpaceus: Effect of wind on orientation and timing of migration. Journal of Avian Biology 33:349-357.

Alerstam, T. (1990). Bird Migration. Cambridge University Press, Cambridge, UK.

Alerstam, T. (2011). Optimal bird migration revisited. Journal of Ornithology 152:5-23.

Alerstam, T., and Å. Lindström (1990). Optimal bird migration: The relative importance of time, energy, and safety. In Bird Migration: Physiology and Ecophysiology (E. Gwinner, Editor). Springer Berlin, Heidelberg, Germany. pp. 331-351.

Anderson, A. M., S. Duijns, P. A. Smith, C. Friis, and E. Nol (2019). Migration distance and body condition influence shorebird migration strategies and stopover decisions during southbound migration. Frontiers in Ecology and Evolution 7:1-14.

Arizaga, J., E. J. Belda, and E. Barba (2011). Effect of fuel load, date, rain and wind on departure decisions of a migratory passerine. Journal of Ornithology 152:991-999.

Bächler, E., and M. Schaub (2007). The effects of permanent local emigration and encounter technique on stopover duration estimates as revealed by telemetry and mark-recapture. The Condor 109:142-154.

Bargain, B., C. Vansteenwegen, and J. Henry (2002). Importance des marais de la baie d'Audierne (Bretagne) pour la migration du Phragmite des joncs Acrocephalus schoenobaenus. Alauda 70:37-55.

Bayly, N. J. (2006). Optimality in avian migratory fuelling behaviour: A study of a trans-Saharan migrant. Animal Behaviour 71:173-182.

Bayly, N. J. (2007). Extreme fattening by Sedge Warblers, Acrocephalus schoenobaenus, is not triggered by food availability alone. Animal Behaviour 74:471-479.

Bibby, C. J., and R. E. Green (1981). Autumn migration strategies of Reed and Sedge Warblers. Ornis Scandinavica 12:1-12.

Clark, C. W., and M. Mangel (2000). Dynamic State Variable Models in Ecology: Methods and Applications. Oxford University Press, New York, NY, USA.

Cohen, E. B., F. R. Moore, and R. A. Fischer (2014). Fuel stores, time of spring, and movement behavior influence stopover duration of Red-eyed Vireo Vireo olivaceus. Journal of Ornithology 155:785-792.

Crosbie, S. F., and B. F. J. Manly (1985). Parsimonious modelling of capture-mark-recapture studies. Biometrics 41:385.

Dänhardt, J., and Å. Lindström (2001). Optimal departure decisions of songbirds from an experimental stopover site and the significance of weather. Animal Behaviour 62:235-243.

Dehorter, O., and CRBPO (2015). Bird ringing and movement database for France. Centre de Recherches sur la Biologie des Populations d'Oiseaux, Muséum National d'Histoire Naturelle, Paris, France. http://crbpo.mnhn.fr/

Deppe, J. L., M. P. Ward, R. T. Bolus, R. H. Diehl, A. Celis-Murillo, T. J. Zenzal, F. R. Moore, T. J. Benson, J. A. Smolinsky, L. N. Schofield, et al. (2015). Fat, weather, and date affect migratory songbirds' departure decisions, routes, and time it takes to cross the Gulf of Mexico. Proceedings of the National Academy of Sciences USA 112:E6331-E6338.

Dossman, B. C., G. W. Mitchell, D. R. Norris, P. D. Taylor, C. G. Guglielmo, S. N. Matthews, and P. G. Rodewald (2016). The effects of wind and fuel stores on stopover departure behavior across a migratory barrier. Behavioral Ecology 27:567-574.

Eikenaar, C., A. Hegemann, F. Packmor, I. Kleudgen, and C. Isaksson (2020a). Not just fuel: Energy stores are correlated with immune function and oxidative damage in a long-distance migrant. Current Zoology 66:21-28.

Eikenaar, C., and J. L. Schläfke (2013). Size and accumulation of fuel reserves at stopover predict nocturnal restlessness in a migratory bird. Biology letters 9:20130712.

Eikenaar, C., E. Winslott, S. Hessler, and C. Isaksson (2020b). Oxidative damage to lipids is rapidly reduced during migratory stopovers. Functional Ecology 34:1215-1222.

Erni, B., F. Liechti, L. G. Underhill, and B. Bruderer (2002). Wind and rain govern the intensity of nocturnal bird migration in central Europe-A log-linear regression analysis. Ardea 90:155-166.

Fontanilles, P., I. De la Hera, K. Sourdrille, F. Lacoste, and C. Kerbiriou (2020). Stopover ecology of autumn-migrating Bluethroats (Luscinia svecica) in a highly anthropogenic river basin. Journal of Ornithology 161:89-101. 
Fuchs, T., A. Haney, T. J. Jechura, F. R. Moore, and V. P. Bingman (2006). Daytime naps in night-migrating birds: Behavioural adaptation to seasonal sleep deprivation in the Swainson's Thrush, Catharus ustulatus. Animal Behaviour 72:951-958.

Fuchs, T., D. Maury, F. R. Moore, and V. P. Bingman (2009). Daytime micro-naps in a nocturnal migrant: An EEG analysis. Biology Letters $5: 77-80$

Gimenez, O., V. Rossi, R. Choquet, C. Dehais, B. Doris, H. Varella, J. P. Vila, and R. Pradel (2007). State-space modelling of data on marked individuals. Ecological Modelling 206:431-438.

Goymann, W., F. Spina, A. Ferri, and L. Fusani (2010). Body fat influences departure from stopover sites in migratory birds: Evidence from whole-island telemetry. Biology Letters 6:478-481.

Green, M., T. Alerstam, P. Clausen, R. Drent, and B. S. Ebbinge (2002). Dark-bellied Brent Geese Branta bernicla bernicla, as recorded by satellite telemetry, do not minimize flight distance during spring migration. Ibis 144:106-121.

Hair, J. F., W. C. Black, B. J. Babin, R. E. Anderson, and R. L. Tatham (2006). Multivariate Data Analysis, sixth edition. Pearson, London, UK.

Hake, M., N. Kjellén, and T. Alerstam (2003). Age-dependent migration strategy in Honey Buzzards Pernis apivorus tracked by satellite. Oikos 103:385-396.

Hedenström, A., and T. Alerstam (1997). Optimum fuel loads in migratory birds: Distinguishing between time and energy minimization. Journal of Theoretical Biology 189:227-234.

Hornik, K., F. Leisch, A. Zeileis, and M. Plummer (2003). JAGS: A program for analysis of Bayesian graphical models using Gibbs sampling. In Proceedings of the 3rd International Workshop on Distributed Statistical Computing (DSC 2003), March 20-22, 2003 (K. Hornik, F. Leisch, and A. Zeileis, Editors). Technische Universität Wien, Vienna, Austria.

Jenni, L., and M. Schaub (2003). Behavioural and physiological reactions to environmental variation in bird migration: A review. In Avian Migration (B. Peter, E. Gwinner, and E. Sonnenschein, Editors). Springer Berlin, Heidelberg, Germany. pp. 155-171.

Jolly, G. M. (1965). Explicit estimates from capture-recapture data with both death and immigration-stochastic model. Biometrika $52: 225$.

Kéry, M., and M. Schaub (2011). Bayesian Population Analysis using WinBUGS: A Hierarchical Perspective. Academic Press, Waltham, MA, USA.

Klinner, T., J. Buddemeier, F. Bairlein, and H. Schmaljohann (2020). Decision-making in migratory birds at stopover: An interplay of energy stores and feeding conditions. Behavioral Ecology and Sociobiology 74:1-14.

Klinner, T., and H. Schmaljohann (2020). Temperature change is an important departure cue in nocturnal migrants: Controlled experiments with wild-caught birds in a proof-of-concept study. Proceedings of the Royal Society B: Biological Sciences 287:20201650.

Ktitorov, P., A. Tsvey, and A. Mukhin (2010). The good and the bad stopover: Behaviours of migrant reed warblers at two contrasting sites. Behavioral Ecology and Sociobiology 64:1135-1143.

Lank, D. B., R. W. Butler, J. Ireland, and R. C. Ydenberg (2003). Effects of predation danger on migration strategies of sand pipers. Oikos 103:303-319.

Liechti, F. (2006). Birds: Blowin' by the wind? Journal of Ornithology 147:202-211.

Linscott, J. A., and N. R. Senner (2021). Beyond refueling: Investigating the diversity of functions of migratory stopover events. Ornithological Applications 123:1. https://doi. org/10.1093/ornithapp/duaa074

Lok, T., C. J. Hassell, T. Piersma, R. Pradel, and O. Gimenez (2019). Accounting for heterogeneity when estimating stopover duration, timing and population size of Red Knots along the Luannan Coast of Bohai Bay, China. Ecology and Evolution 9:6176-6188.

Lyons, J. E., W. L. Kendall, J. A. Royle, S. J. Converse, B. A. Andres, and J. B. Buchanan (2016). Population size and stopover duration estimation using mark-resight data and Bayesian analysis of a superpopulation model. Biometrics 72:262-271.

Ma, Z., N. Hua, X. Zhang, H. Guo, B. Zhao, Q. Ma, W. Xue, and C. Tang (2011). Wind conditions affect stopover decisions and fuel stores of shorebirds migrating through the south Yellow Sea. Ibis 153:755-767.

McKinnon, E. A., K. C. Fraser, C. Q. Stanley, and B. J. M. Stutchbury (2014). Tracking from the tropics reveals behaviour of juvenile songbirds on their first spring migration. PLoS One 9:e105605.

McWilliams, S. R., C. Guglielmo, B. Pierce, and M. Klaassen (2004). Flying, fasting, and feeding in birds during migration: A nutritional and physiological ecology perspective. Journal of Avian Biology 35:377-393.

Mills, A. M., B. G. Thurber, S. A. Mackenzie, and P. D. Taylor (2011). Passerines use nocturnal flights for landscapescale movements during migration stopover. The Condor 113:597-607.

Mitchell, G. W., B. K. Woodworth, P. D. Taylor, and D. R. Norris (2015). Automated telemetry reveals age specific differences in flight duration and speed are driven by wind conditions in a migratory songbird. Movement Ecology 3:1-13.

Moore, F. R., K. M. Covino, W. B. Lewis, T. J. Zenzal, and T. J. Benson (2017). Effect of fuel deposition rate on departure fuel load of migratory songbirds during spring stopover along the northern coast of the Gulf of Mexico. Journal of Avian Biology 48:123-132.

Müller, F., C. Eikenaar, Z. J. Crysler, P. D. Taylor, and H. Schmaljohann (2018). Nocturnal departure timing in songbirds facing distinct migratory challenges. Journal of Animal Ecology 87:1102-1115.

Németh, Z. (2009). Observation of daytime sleep-like behavior in a migratory songbird during stopover. The Wilson Journal of Ornithology 121:644-646.

Packmor, F., T. Klinner, B. K. Woodworth, C. Eikenaar, and H. Schmaljohann (2020). Stopover departure decisions in songbirds: Do longdistance migrants depart earlier and more independently of weather conditions than medium-distance migrants? Movement Ecology 8:1-14. 
Péron, G., P. Y. Henry, P. Provost, O. Dehorter, and R. Julliard (2007). Climate changes and post-nuptial migration strategy by two reedbed passerines. Climate Research 35:147-157.

Pledger, S., M. Efford, K. Pollock, J. Collazo, and J. Lyons (2008). Stopover duration analysis with departure probability dependent on unknown time since arrival. In Modeling Demographic Processes in Marked Populations (D. L. Thomson, E. G. Cooch, and M. J. Conroy, Editors). Springer, New York, NY, USA. pp. 349-363.

R Development Core Team (2013). A Language and Environment for Statistical Computing. R Foundation for Statistical Computing, Vienna, Austria. https://www.R-project.org

Reilly, J. R., and R. J. Reilly (2009). Bet-hedging and the orientation of juvenile passerines in fall migration. Journal of Animal Ecology 78:990-1001.

Rguibi-Idrissi, H., R. Julliard, and F. Bairlein (2003). Variation in the stopover duration of Reed Warblers Acrocephalus scirpaceus in Morocco: Effects of season, age and site. Ibis 145:650-656.

Richardson, W. J. (1990). Timing of bird migration in relation to weather: Updated review. In Bird Migration: Physiology and Ecophysiology (E. Gwinner, Editor). Springer Berlin, Heidelberg, Germany. pp. 78-101.

Richardson, W. J. (1991). Wind and orientation of migrating birds: A review. Orientation in Birds 60:226-249.

Roques, S., D. B. Lank, E. Cam, and R. Pradel (2021). More than just refuelling: Lengthy stopover and selection of departure weather by sandpipers prior to transoceanic and transcontinental flights. Ibis 163:519-535.

Royle, J. A. (2008). Modeling individual effects in the CormackJolly-Seber model: A state-space formulation. Biometrics 64:364-370.

Schaub, M., and L. Jenni (1999). Does tape-luring of migrating Eurasian Reed-Warblers increase number of recruits or capture probability? The Auk 116:1047-1053.

Schaub, M., L. Jenni, and F. Bairlein (2008). Fuel stores, fuel accumulation, and the decision to depart from a migration stopover site. Behavioral Ecology 19:657-666.

Schaub, M., F. Liechti, and L. Jenni (2004). Departure of migrating European Robins, Erithacus rubecula, from a stopover site in relation to wind and rain. Animal Behaviour 67:229-237.

Schaub, M., R. Pradel, L. Jenni, and J. D. Lebreton (2001). Migrating birds stop over longer than usually thought: An improved capturerecapture analysis. Ecology 82:852-859.

Schmaljohann, H. (2018). Proximate mechanisms affecting seasonal differences in migration speed of avian species. Scientific Reports 8:1-10.

Schmaljohann, H., and C. Eikenaar (2017). How do energy stores and changes in these affect departure decisions by migratory birds? A critical view on stopover ecology studies and some future perspectives. Journal of Comparative Physiology A 203:411-429.

Schmaljohann, H., J. W. Fox, and F. Bairlein (2012). Phenotypic response to environmental cues, orientation and migration costs in songbirds flying halfway around the world. Animal Behaviour 84:623-640.

Schmaljohann, H., F. Korner-Nievergelt, B. Naef-Daenzer, R. Nagel, I. Maggini, M. Bulte, and F. Bairlein (2013). Stopover optimization in a long-distance migrant: The role of fuel load and nocturnal take-off time in Alaskan Northern Wheatears (Oenanthe oenanthe). Frontiers in Zoology 10:26.

Schmaljohann, H., S. Lisovski, and F. Bairlein (2017). Flexible reaction norms to environmental variables along the migration route and the significance of stopover duration for total speed of migration in a songbird migrant. Frontiers in Zoology 14:17.

Schwarz, C. J., and A. N. Arnason (1996). A general methodology for the analysis of capture-recapture experiments in open populations. Biometrics 52:860.

Schwilch, R., and L. Jenni (2001). Low initial refueling rate at stopover sites: A methodological effect? The Auk 118:698-708.

Schwilch, R., L. Jenni, T. Piersma, and N. M. A. Holmgren (2002). Do migratory birds need a nap after a long non-stop flight? Ardea 90:149-154.

Seber, G. A. F. (1965). A note on the multiple-recapture census. Biometrika 52:249.

Sergio, F., A. Tanferna, R. De Stephanis, L. L. Jiménez, J. Blas, G. Tavecchia, D. Preatoni, and F. Hiraldo (2014). Individual improvements and selective mortality shape lifelong migratory performance. Nature 515:410-413.

Shamoun-Baranes, J., F. Liechti, and W. M. G. Vansteelant (2017). Atmospheric conditions create freeways, detours and tailbacks for migrating birds. Journal of Comparative Physiology A 203:509-529.

Sjöberg, S., T. Alerstam, S. Åkesson, A. Schulz, A. Weidauer, T. Coppack, and R. Muheim (2015). Weather and fuel reserves determine departure and flight decisions in passerines migrating across the Baltic Sea. Animal Behaviour 104:59-68.

Skrip, M. M., U. Bauchinger, W. Goymann, L. Fusani, M. Cardinale, R. R. Alan, and S. R. Mcwilliams (2015). Migrating songbirds on stopover prepare for, and recover from, oxidative challenges posed by long-distance flight. Ecology and Evolution 5:3198-3209.

Smith, A. D., and S. R. McWilliams (2014). What to do when stopping over: Behavioral decisions of a migrating songbird during stopover are dictated by initial change in their body condition and mediated by key environmental conditions. Behavioral Ecology 25:14231435.

Somveille, M., A. S. L. Rodrigues, and A. Manica (2015). Why do birds migrate? A macroecological perspective. Global Ecology and Biogeography 24:664-674.

Somveille, M., A. S. L. Rodrigues, and A. Manica (2018). Energy efficiency drives the global seasonal distribution of birds. Nature Ecology and Evolution 2:962-969.

Su, Y.-S., M. Yajima, M. Y.-S. Su, and J. SystemRequirements (2015). Package “R2jags." R package version 0.03-08. http://CRAN. R-project. org/package $=$ R2jags 
Taylor, P. D., S. A. Mackenzie, B. G. Thurber, A. M. Calvert, A. M. Mills, L. P. McGuire, and C. G. Guglielmo (2011). Landscape movements of migratory birds and bats reveal an expanded scale of stopover. PLoS One 6:e27054.

Tsvey, A., V. N. Bulyuk, and V. Kosarev (2007). Influence of body condition and weather on departures of first-year European Robins, Erithacus rubecula, from an autumn migratory stopover site. Behavioral Ecology and Sociobiology 61:1665-1674.

Warnock, N. (2010). Stopping vs. staging: The difference between a hop and a jump. Journal of Avian Biology 41:621-626.

Wikelski, M., A. Raim, E. M. Tarlow, R. P. Larkin, G. H. Visser, and R. H. Diehl (2003). Costs of migration in free-flying songbirds. Nature 423:704-704.

Zehnder, S., S. Åkesson, F. Liechti, and B. Bruderer (2001). Nocturnal autumn bird migration at Falsterbo, South Sweden. Journal of Avian Biology 32:239-248.

Zúñiga, D., Y. Gager, H. Kokko, A. M. Fudickar, A. Schmidt, B. NaefDaenzer, M. Wikelski, and J. Partecke (2017). Migration confers winter survival benefits in a partially migratory songbird. elife 6:1-12. 